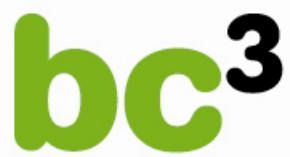

BASQUE CENTRE

FOR CLIMATE CHANGE

Klima Aldaketa Ikergai

\title{
The Private Provision of International Impure Public Goods: the Case of Climate Policy
}

Martin Altemeyer-Bartscher, Anil Markandya and Dirk Rübbelke

September 2011

BC3 WORKING PAPER SERIES

2011-09 
The Basque Centre for Climate Change (BC3) is a Research Centre based in the Basque Country, which aims at contributing to long-term research on the causes and consequences of Climate Change in order to foster the creation of knowledge in this multidisciplinary science.

The BC3 promotes a highly-qualified team of researchers with the primary objective of achieving excellence in research, training and dissemination. The Scientific Plan of BC3 is led by the Scientific Director, Prof. Anil Markandya.

The core research avenues are:

- $\quad$ Adaptation to and the impacts of climate change

- $\quad$ Measures to mitigate the amount of climate change experienced

- $\quad$ International Dimensions of Climate Policy

- $\quad$ Developing and supporting research that informs climate policy in the Basque Country

See www.bc3research.org for further details.

The BC3 Working Paper Series is available on the internet at http://www.bc3research.org/working_papers/view.html

Enquiries (Regarding the BC3 Working Paper Series):

Roger Fouquet

Email: roger.fouquet@bc3research.org

The opinions expressed in this working paper do not necessarily reflect the position of Basque Centre for Climate Change (BC3) as a whole.

Note: If printed, please remember to print on both sides. Also, perhaps try two pages on one side. 


\title{
The Private Provision of International Impure Public Goods: the Case of Climate Policy
}

\author{
Martin Altemeyer-Bartscher* \\ Anil Markandya** \\ Dirk T.G. Rübbelke***
}

September 2011

\begin{abstract}
We discuss a tax-transfer scheme that aims at addressing the under-provision problem associated with the private supply of international public goods and at bringing about Pareto optimal allocations internationally. In particular, we consider the example of the global public good 'climate stabilisation', both in an analytical and a numerical simulation model. The proposed scheme levies Pigouvian taxes globally, while international sidepayments are employed in order to provide incentives to individual countries for not taking a free-ride from the international Pigouvian tax scheme. The side-payments, in turn, are financed via the environmental taxes. As a distinctive feature we take into account ancillary benefits that may be associated with local public characteristics of climate policy. We determine the positive impact that ancillary effects may exert on the scope for financing side-payments via environmental taxation. A particular attractive feature of ancillary benefits is that they arise shortly after the implementation of climate policies and therefore yield an almost immediate payback of investments in abatement efforts. Especially in times of high public debt levels, long periods of amortisation would tend to reduce political support for investments in climate policy.
\end{abstract}

Keywords: ancillary benefits, climate policy, impure public goods, environmental taxation, international transfers

JEL Classification: Q38, H23, D62

Cite as: Altemeyer-Bartscher, M., Markandya, A. and Rübbelke, D. (2011), The Private Provision of International Impure Public Goods: the Case of Climate Policy. BC3 Working Paper Series 2011-09. Basque Centre for Climate Change (BC3). Bilbao, Spain.

\footnotetext{
* Department of Economics, Chemnitz University of Technology, 09107 Chemnitz, Germany, email: martin.altemeyer-bartscher@wirtschaft.tu-chemnitz.de

** Basque Centre for Climate Change (BC3), 48008 Bilbao, Spain, and IKERBASQUE - Basque Foundation for Science, 48011 Bilbao, Spain, email: a.markandya@bc3research.org

*** Basque Centre for Climate Change (BC3), 48008 Bilbao, Spain, and IKERBASQUE - Basque Foundation for Science, 48011 Bilbao, Spain, email: dirk.ruebbelke@bc3research.org
} 


\section{Introduction}

The under-provision of global public goods poses a big challenge, since no international coercive authority exists which might enforce an efficient supply of the goods in question. Effective schemes inducing individual countries to voluntarily bring about a Pareto-efficient provision of such goods are sorely needed. This becomes apparent when we take a look at the current efforts to combat global warming, i.e. to provide the global public good 'climate protection'. The Kyoto Protocol limiting the greenhouse gas (GHG) emissions of most industrialized countries will expire by end of 2012 and the international community is encountering large difficulties in agreeing upon an adequate postKyoto regime.

In general, two different strategies for negotiating and designing a future international climate protection regime can be distinguished: Firstly, as in the past and with the Kyoto Protocol, countries can - as a first step - negotiate fixed GHG abatement targets, e.g. the EU-15 had committed to reduce its emissions by 8 per cent in the period 1990-2008/12. Then - as a second step - committed countries launch national environmental programmes to attain their individual abatement targets. During the commitment period of the Kyoto Protocol, countries have employed amongst others price-influencing instruments, like emission trading or carbon taxes, in order to pursue their individual Kyoto targets.

Secondly and alternatively, in order to address the inefficient under-provision of public goods, the manipulation of prices can be pursued directly at the international negotiation stage by stipulating an agreement which itself evokes such manipulations. Hence, instead of negotiating and arranging absolute abatement targets in an international agreement, countries negotiate the ways in which prices are modified. The aim is to agree upon the parameters of such manipulations so as to bring about an efficient outcome of the private provision of public goods by individual countries. Put it differently, the manipulated prices should induce - still selfishly acting - individual governments to behave in a way that is compatible with global welfare maximization. It is such international price-influencing schemes we are interested in. 
In recent years several different price-influencing schemes have been proposed as a tool for international climate policy. Barrett (1990), Rübbelke (2006), Boadway, Song and Tremblay (2007, 2011) and Fujita (2011) suggested applyingmatching schemes in order to address the inefficiency in global climate protection.By matching, which is an approach that was first proposed by Guttman (1978, 1987), governments negotiate about so-called matching rates, i.e. rates at which they - conditionally on other countries' contributions provide additional climate protection efforts. In this way, governments mutually subsidize climate policy. As Buchholz, Cornes and Rübbelke (2011) demonstrate, these matching schemes are equivalent to so-called tax-subsidy schemes, which have been proposed, e.g. by Andreoni and Bergstrom (1996) as well as Falkinger (1996). In particular, Falkinger, Hackl and Pruckner (1996) suggest applying these schemes to induce an efficient private provision of public goods in the sphere of international climate protection. Due to the subsidization within matching or tax-subsidy schemes, the effective price or marginal cost of climate protection is reduced so that it becomes more attractive for governments to contribute to the public good 'global climate protection/ stabilisation'.

In the price-influencing nature somehow related to such schemes, Nordhaus (2006) recommends implementing a global Pigouvian tax scheme and employing side-payments in order to provide incentives for all countries to participate in this global scheme. Altemeyer-Bartscher, Rübbelke and Sheshinski (2010) have recently elaborated on how this scheme could be implemented internationally. Their scheme deviates from matching and taxsubsidy schemes in the way that it explicitly distinguishes two distinct layers of involved agents: governments and private agents (households in their model). Governments negotiate tax rates as well as international side-payments, but since the international transfers are provided in a lump-sum fashion, they do not experience modifications of the marginal cost of climate policy. Yet, becausecountries directly negotiate tax rates,they influence the price of GHG emitting activities in the subordinate private household sector. Environmental taxation raises the cost of polluting activities and therefore provides additional incentives for households to reduce emissions. 
In this paper we focus on a generalisation of the proposal by AltemeyerBartscher, Rübbelke and Sheshinski (ARS) (2010) which is based on Nordhaus' (2006) Pigouvian tax approach. In contrast to the ARS approach, we take into account that climate policy is a global impure public and not a pure public good. ${ }^{1}$ Impure publicness results from the fact that, apart from climate stabilisation which is purely public on a global scale, climate policy is also associated with local ancillary benefits such as a reduction of air pollution, traffic congestion, or noise (see e.g. OECD 2000 and IPCC 2001). We investigate whether and how the occurrence of these privatising features, i.e. the ancillary effects which represent private effects from a whole region's or country's point of view, of climate policy affect the functioning of international climate negotiations on environmental taxation. In addition to an analytical assessment of the problem, we also investigate the influence of ancillary benefits on the functionality of the proposed scheme in a numerical simulation model.

The paper is organised as follows. In Section 2, we distinguish the main features of primary and ancillary benefits of climate policy. Thereafter, in Section 3, we present the basic set-up of the analytical model, which we employ in Section 4 to depict international negotiations on environmental tax rates and sidepayments. Side-payments are financed via the tax revenue obtained from the environmental tax and climate policy is treated as an impure public good. In Section 5, in a numerical simulation model we ascertain the potential influence ancillary effects might exert on environmental tax revenues and hence on available funds for international transfers. Tax revenues tend to increase due to ancillary effects as long as the price elasticity of demand for consuming the polluting good is not very high. Concerning this matter empirical literature provides evidence for a rather price-inelastic demand for gasoline (Brons et al. 2008), for example. Section 6 draws conclusions and puts our results in a broader context. As we will discuss, not only the magnitude of benefits might be important for decision-makers, but also the inter-temporal distribution of costs and benefits of policies.

\footnotetext{
${ }^{1}$ On impure public goods also see Cornes and Sandler $(1994,1996)$. Impure public goods in the context of environmental protection have recently been discussed, e.g. by Rübbelke (2003) and Kotchen $(2005,2006)$.
} 


\section{Primary and Ancillary Benefits}

Benefits of climate policy arise from the prevention of economic and environmental damages. Two different kinds of benefits, i.e. primary and ancillary benefits, are produced simultaneously. Primary benefits are the benefits derived from pursuing climate policy's primary aim, which is climate stabilization (Markandya and Rübbelke 2004). In contrast to primary benefits, the ancillary benefits are, according to the IPCC (2001), "the monetized secondary, or side benefits of mitigation policies on problems such as reductions in local air pollution associated with the reduction of fossil fuels, and possibly indirect effects on congestion, land quality, employment, and fuel security." We distinguish primary and ancillary benefits with respect to two of their main features, i.e. 1) geographical occurrence and 2) inter-temporal occurrence of benefits.

\section{Geographical occurrence}

Climate-threatening consumption like the burning of fossil fuels regularly has three different characteristics or effects: a private effect to the individual consumer and two negative externalities of which one is global, while the other is more domestic from an individual country's point of view (see Figure 1).

Private effect to the consumer: A private household obtains some private benefit from burning fossil fuels, e.g. because it might allow the household members to travel by car or heat the home.

Global externalities: By emitting GHGs, this burning also contributes to climate destabilization, i.e. global warming, which in turn generates costs globally. These costs could be mitigated by policies stabilizing the climate and the respective prevented costs are tagged as 'primary benefits'. These benefits can be enjoyed everywhere in the world, i.e. the merits from climate stabilization are non-excludable; furthermore, there is non-rivalry in the consumption of these merits. Consequently, 'climate stabilization' is a global public effect of climate policy.

Local/regional externalities: In general, climate threatening activities like the burning of fossil fuels are not only accompanied by GHG emissions but also by the discharge of local or regional air pollutants like particulate matter or sulfur 
dioxide. Therefore, climate policies like carbon taxes, e.g. causing the mitigation of fossil fuel consumption, also improve local or regional air quality. The related benefits are coined 'ancillary benefits' or 'co-benefits', which regularly arise locally or regionally in the direct neighborhood of the place where the climate protection activity was accomplished. ${ }^{2}$ Hence, it is appropriate to consider the co-effect of air-quality improvement as a domestic public effect from the climate protecting country's or region's point of view. ${ }^{3}$

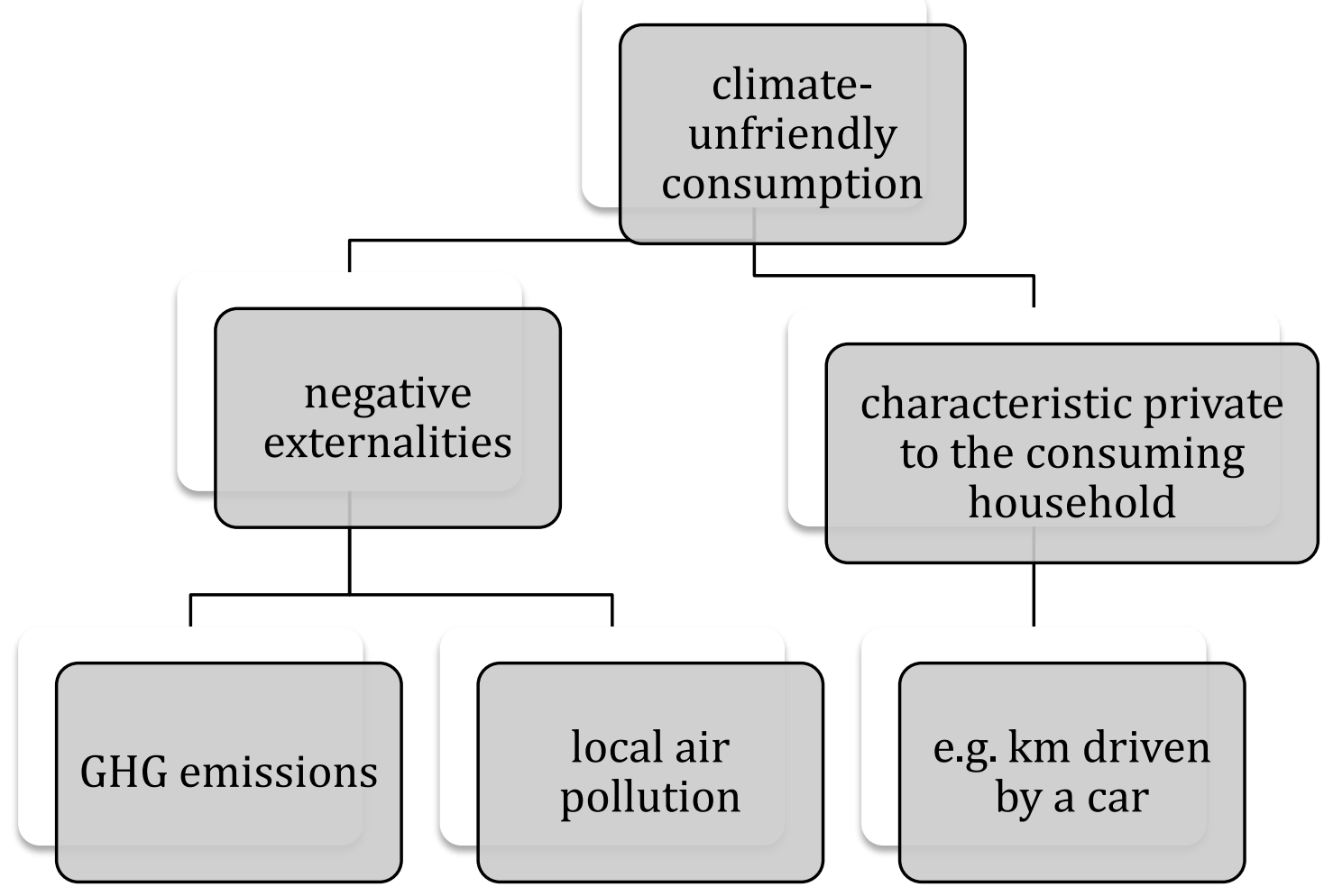

Figure 1: Joint Production of Private, Domestic and Global Characteristics.

\footnotetext{
${ }^{2}$ Longo, Hoyos and Markandya (2011) assess the willingness to pay (WTP) for ancillary and global benefits of climate protection policies in the Basque Country/Spain and their results show that WTP estimates are 53-73\% higher when ancillary benefits are considered.

${ }^{3}$ This assumption is a simplification in the sense that some regional pollutants also spill over beyond national borders. For an analysis of sulfur emissions as transnational pollutants, see e.g. Finus and Tjøtta (2003).
} 
Inter-temporal occurrence

Besides the difference in the geographical impact between primary and ancillary benefits, there is another important distinction to be made: the intervals between the implementation of a climate policy, like a carbon tax, andthe occurrence of benefits differ among primary and ancillary benefits (Ekins 1996). Primary benefits of climate protection measures arise with a delay of about a half-century, which is due to thermal inertia on our planet. This means that, in order to obtain primary benefits, some investment in climate policy has to be made which will only be paid back in an uncertain distant future. For decisionmakers the justification of investments in climate protection projects bringing about uncertain future benefits is a challenging task, which is exacerbated by the current financial crisis and high public debt levels.

In contrast, ancillary benefits can be largely enjoyed (almost) instantly, since the avoided damages, e.g. from air pollution or noise, would have otherwise occurred immediately or shortly after the GHG emitting activity. Consequently, ancillary benefits constitute an immediate payback of investments, so that long periods for the amortization of any debts incurred in implementing the policy are prevented.

\section{The Basic Model}

\subsection{Transboundary Pollution Spillovers}

We consider two countries, indexed by $i(i=1,2)$ in which private consumption generates a negative global spillover effects (GHG emissions) that harms all countries as well as negative domestic externalities in the shape of local emissions that exclusively affects the emitting country. ${ }^{4}$ In country $i$ a representative household's production of both externalities accompanies its consumption of a polluting private good, which amounts to $x_{i}$. It also consumes a second (clean) private good of the amount $y_{i}$, which is not associated with any externality. It is assumed that households behave competitively, i.e., they ignore their own effect on total pollution. Furthermore, they take the other agents' pollution levels as given. The global level of environmental externalities

${ }^{4}$ The case of one-sided spillovers has been analyzed by Rübbelke and Sheshinski (2005). 
perceived in country $i$ amounts to $\phi_{2}=\phi_{2}\left(X_{1}, X_{2}\right)=\phi_{2}\left(X_{1}+X_{2}\right)$ where $X_{1}$ represents the total amount of the pollution-generating private good consumption in country 1 and $X_{2}$ is the respective consumption in country 2 . By means of the specific functional form of $\phi_{2}$ we take into account that global environmental externalities are determined by the aggregated global greenhouse gas (GHG) emissions caused by the consumption of the polluting private good. Such pollution is a perfect substitute among countries, i.e. it does not make a difference for either country where the GHG emission is produced. The domestic pollution in country $i$ is represented by $\phi_{1}=\phi_{1}\left(X_{1}\right)$. An eco-tax in the shape of an excise tax is levied which burdens the consumption of the polluting commodity. ${ }^{5}$

\section{The Individual Household's Maximization Problem}

The maximization problem of a representative household in country $i$ can be expressed as follows:

$$
\begin{aligned}
& \max u_{i}\left(x_{i}, y_{i}, \phi_{1 i}, \phi_{2}\right) \\
& \text { s.t. }\left(p+t_{i}\right) x_{i}+y_{i}=m_{i}+\tau_{i}-\sigma_{i},
\end{aligned}
$$

where $m_{i}$ denotes the level of the representative household's income, $t_{i}$ denotes the excise tax rate, $\tau_{i}=t_{i} \cdot x_{i}$ stands for the tax funds raised from the representative household and $\sigma_{i}$ is the amount of tax funds $\tau_{i}$ redistributed to others, such that $\tau_{i}-\sigma_{i}$ is the amount of tax funds which the representative household gets back from its government. It is assumed that the households are naive, i.e., they do not consider the effects of their behavior on $\tau_{i}$ and $\sigma_{i}$. This is plausible because the impact of a single household onto the rest of the world is negligible.

\footnotetext{
5"In the case of reciprocal consumption externalities, the common interpretation of the Pigouvian principle calls for taxes on the externality-creating commodities" (Green and Sheshinski 1976: 798).
} 
We obtain the following first-order conditions:

$$
\begin{aligned}
& \frac{\partial u_{i}}{\partial x_{i}}\left(x_{i}, y_{i}, \phi_{1 i}, \phi_{2}\right)-\lambda\left(p+t_{i}\right)=0, \\
& \frac{\partial u_{i}}{\partial y_{i}}\left(x_{i}, y_{i}, \phi_{1 i}, \phi_{2}\right)-\lambda=0, \\
& p x_{i}+y_{i}-m_{i}+\sigma_{i}=0 .
\end{aligned}
$$

\subsection{Take-it-or-leave-it Offer}

Regional welfare maximizing decision makers in country $i$ do not take into account negative external effects they exert on their neighboring country $j(j=1,2$ and $j \neq i)$ and hence raise inefficiently low eco-taxes on the consumption of the dirty good $\mathrm{X}_{1}$. One method of coordinating environmental policy among regions to overcome inefficiently high transnational externality production is the implementation of a system of international side-payments. We assume that each country can make a take-it-or-leave-it offer. Country $i$, for example, could offer $\left(S_{j}, t_{j}\right)$, i.e. country $i$ offers a transfer payment $S_{j}$ which is channeled to country $j$ in order to induce this country to raise its eco-tax rate $t_{j}$ to a certain level desired by $i$. Country $j$ can either accept or reject the offer. We assume that both countries can make binding commitments with respect to their transfer payment and eco-tax levels. Local governments simultaneously offer take-it-or-leave-it contracts. In doing so, each country anticipates the subject matter $\left(S_{k}, t_{k}\right)$, with $k=i, j$, of the contract offered by the opponent.

\subsection{The First-best Policy}

As a reference scenario we examine the maximization problem of a social planner who maximizes global welfare in our two-country world, i.e. the sum of both countries' welfare. We suppose that a country's welfare level is equal to the sum of the welfare levels enjoyed by the individual households located in the respective country: 


$$
\max _{X_{1}, X_{2}} W=U_{1}\left(X_{1}, \phi_{11}, \phi_{2}\right)+U_{2}\left(X_{2}, \phi_{12}, \phi_{2}\right)
$$

s.t. $p\left(X_{1}+X_{2}\right)+Y_{1}+Y_{2}=M$,

Where $M_{1}+M_{2}=M$ denotes the sum of national income $M_{1}$ in country 1 and of national income $M_{2}$ in country 2 . The first-order conditions are:

$$
\begin{aligned}
& \frac{\partial U_{1}}{\partial X_{1}}+\frac{\partial U_{1}}{\partial \phi_{11}} \frac{\partial \phi_{11}}{\partial X_{1}}+\frac{\partial U_{1}}{\partial \phi_{2}} \frac{\partial \phi_{2}}{\partial X_{1}}+\frac{\partial U_{2}}{\partial \phi_{2}} \frac{\partial \phi_{2}}{\partial X_{1}}=p \lambda \\
& \frac{\partial U_{2}}{\partial X_{2}}+\frac{\partial U_{2}}{\partial \phi_{12}} \frac{\partial \phi_{12}}{\partial X_{2}}+\frac{\partial U_{2}}{\partial \phi_{2}} \frac{\partial \phi_{2}}{\partial X_{2}}+\frac{\partial U_{1}}{\partial \phi_{2}} \frac{\partial \phi_{2}}{\partial X_{2}}=p \lambda,
\end{aligned}
$$

where the third terms on the LHS of (5) and (6) respectively denote the marginal external effects of pollution. From equations (5) and (6) as well as equation (7) we obtain the Pareto-efficient tax rates:

$$
t_{1}^{f b}=\frac{\frac{\partial U_{1}}{\partial X_{1}}}{\lambda}-p=-\frac{\frac{\partial U_{1} \partial \phi_{11}}{\partial \phi_{11} \partial X_{1}}+\frac{\partial U_{1} \partial \phi_{2}}{\partial \phi_{2} \partial X_{1}}+\frac{\partial U_{2} \partial \phi_{2}}{\partial \phi_{2} \partial X_{1}}}{\lambda}
$$

and

$$
t_{2}^{f b}=\frac{\frac{\partial U_{2}}{\partial X_{2}}}{\lambda}-p=-\frac{\frac{\partial U_{2} \partial \phi_{12}}{\partial \phi_{12} \partial X_{2}}+\frac{\partial U_{2} \partial \phi_{2}}{\partial \phi_{2} \partial X_{2}}+\frac{\partial U_{1} \partial \phi_{2}}{\partial \phi_{2} \partial X_{2}}}{\lambda} .
$$

The first-best optimal eco-tax policy $\left(t_{1}^{f b}, t_{2}^{f b}\right)$ fully internalises local as well as global pollution externalities.

\section{Decentralized Policy}

Let us turn to the case where individual countries voluntarily negotiate about international pollution abatement. Each individual country's welfare is affected by pollution $\phi_{2}$. The pollution in turn depends on the consumption level in both 
countries, so that both countries will have incentives to offer a take-it-or-leave-it contract to their neighbor in order to influence the eco-tax policy of the opponent.

\subsection{Relationship between Taxes and Transfers in Country 2}

The government of country 1 could benefit by inducing country 2 to raise an eco-tax. We suppose that country 1 will therefore provide a take-it-or-leave-it offer to country 2. However, in the case of reciprocal externalities - which we will focus on - country 2 also provides such an offer to its opponent. In order to fulfill the individual rationality condition no country should be better off by unilaterally rejecting the offer of its opponent. Let us consider the condition under which country 2 will accept the other country's offer:

$$
\begin{aligned}
& U_{2}\left(X_{2}\left(t_{2}^{*}, S_{1}, S_{2}, X_{1}\right), Y_{2}\left(t_{2}^{*}, S_{1}, S_{2}, X_{1}\right), \phi_{12}\left(X_{2}\left(t_{2}^{*}, S_{1}, S_{2}, X_{1}\right)\right), \phi_{2}\left(X_{1}, X_{2}\left(t_{2}^{*}, S_{1}, S_{2}, X_{1}\right)\right)\right) \geq \\
& U_{2}\left(X_{2}\left(t_{2}, S_{1}, 0, X_{1}\right), Y_{2}\left(t_{2}, S_{1}, 0, X_{1}\right), \phi_{12}\left(X_{2}\left(t_{2}, S_{1}, 0, X_{1}\right)\right), \phi_{2}\left(X_{1}, X_{2}\left(t_{2}, S_{1}, 0, X_{1}\right)\right)\right),
\end{aligned}
$$

where $S_{2}$ represents the sum of transfers received from country 1 . The LHS of (9) denotes the welfare of country 2 if it accepts country 1 's offer $\left(S_{2}, t_{2}^{*}\right)$. In case of a rejection of the offer it raises an individual rational tax $t_{2}$, which goes along with a national welfare level expressed by the RHS of (9). Accordingly, by (9) it is claimed that country 2 will only accept to raise a tax rate that is stipulated by the opponent player if its utility level after the introduction of the tax remains at least equal to the state in the case of rejection. Further, in equation (9) $X_{2}$ is the equilibrium amount of the polluting good consumed in country 2 and $Y_{2}$ is the respective amount of the second private good.

Assuming that condition (9) holds with equality and total differentiating yields

$$
\begin{aligned}
& \left(\frac{\partial U_{2}}{\partial X_{2}}+\frac{\partial U_{2}}{\partial \phi_{12}} \frac{\partial \phi_{12}}{\partial X_{2}}+\frac{\partial U_{2}}{\partial \phi_{2}} \frac{\partial \phi_{2}}{\partial X_{2}}+\frac{\partial U_{2}}{\partial \phi_{2}} \frac{\partial \phi_{2}}{\partial X_{1}} \frac{\partial X_{1}}{\partial X_{2}}\right)\left(\frac{\partial X_{2}}{\partial t_{2}^{*}}+\frac{\partial X_{2}}{\partial I_{2}} \frac{\partial S_{2}}{\partial t_{2}^{*}}\right)+ \\
& \frac{\partial U_{2}}{\partial Y_{2}}\left(\frac{\partial Y_{2}}{\partial t_{2}^{*}}+\frac{\partial Y_{2}}{\partial I_{2}} \frac{\partial S_{2}}{\partial t_{2}^{*}}\right)=0,
\end{aligned}
$$


where $I_{2}$ is the net income in country 2 . When we take account of conditions (2) and (3) and the differentiation of the sum of all households' budget constraints we can also write:

$$
\left(t_{2}+\frac{\frac{\partial U_{2} \partial \phi_{12}}{\partial \phi_{12} \partial X_{2}}}{\lambda}+\frac{\frac{\partial U_{2} \partial \phi_{2}}{\partial \phi_{2} \partial X_{2}}}{\lambda}+\frac{\frac{\partial U_{2} \partial \phi_{2} \partial X_{1}}{\partial \phi_{2} \partial X_{1} \partial X_{2}}}{\lambda}\right)\left(\frac{\partial X_{2}}{\partial t_{2}}+\frac{\partial X_{2}}{\partial I_{2}} \frac{\partial S_{2}}{\partial t_{2}}\right)+\frac{\partial S_{2}}{\partial t_{2}}=0 .
$$

Rearranging terms yields:

$$
\frac{\partial S_{2}}{\partial t_{2}}=-\frac{\left(t_{2}+\frac{\frac{\partial U_{2}}{\partial \phi_{12}} \frac{\partial \phi_{12}}{\partial X_{2}}+\frac{\partial U_{2} \partial \phi_{2}}{\partial \phi_{2} \partial X_{2}}+\frac{\partial U_{2} \partial \phi_{2} \partial X_{1}}{\partial \phi_{2} \partial X_{1} \partial X_{2}}}{\lambda}\right) \frac{\partial X_{2}}{\partial t_{2}}}{\left(1+\left(t_{2}+\frac{\frac{\partial U_{2}}{\partial \phi_{12}} \frac{\partial \phi_{12}}{\partial X_{2}}+\frac{\partial U_{2} \partial \phi_{2}}{\partial \phi_{2} \partial X_{2}}+\frac{\partial U_{2} \partial \phi_{2} \partial X_{1}}{\partial \phi_{2} \partial X_{1} \partial X_{2}}}{\lambda}\right) \frac{\partial X_{2}}{\partial I_{2}}\right)} .
$$

The amount of money which country 1 must at least pay to country 2 is uniquely determined by the choice of the tax rate $t_{2}$. In particular, it becomes obvious that the transfer payments is an increasing function of $t_{2}$ for all $t_{2}<t_{2}^{*}$. Analogously, we can derive the marginal impact of $t_{1}$ on $S_{1}$.

\subsection{Transfer-paying Country 1's Maximization Problem}

Countries 1 and 2, both intend to maximize national welfare by making take-itor-leave-it offers $\left(S_{2}, t_{2}\right)$ and $\left(S_{1}, t_{1}\right)$, respectively. In the simultaneous-move game country 1 can correctly anticipate $\left(S_{1}, t_{1}\right)$ offered by country 2 and vice versa.

In the equilibrium both countries will accept the offers of their opponents respectively so that we can restrict our analysis to the following maximization problem:

$\max _{\mathrm{t}_{2}} U_{1}\left(X_{1}\left(t_{1}, S_{1}, S_{2}, X_{2}\right), Y_{1}\left(t_{1}, S_{1}, S_{2}, X_{2}\right), \phi_{11}\left(X_{1}, X_{2}\right), \phi_{2}\left(X_{1}, X_{2}\right)\right)$ 
Maximization yields

$$
\begin{aligned}
& \left(\frac{\partial U_{1}}{\partial X_{1}}+\frac{\partial U_{1}}{\partial \phi_{11}} \frac{\partial \phi_{11}}{\partial X_{1}}+\frac{\partial U_{1}}{\partial \phi_{2}} \frac{\partial \phi_{2}}{\partial X_{1}}\right)\left[\frac{\partial X_{1}}{\partial I_{2}} \frac{d S_{2}}{d t_{2}}+\frac{\partial X_{1}}{\partial X_{2}}\left(\frac{\partial X_{2}}{\partial t_{2}}+\frac{\partial X_{2}}{\partial I_{2}} \frac{d S_{2}}{d t_{2}}\right)\right]+ \\
& \frac{\partial U_{1}}{\partial Y_{1}}\left[\frac{\partial Y_{1}}{\partial I_{2}} \frac{d S_{2}}{d t_{2}}+\frac{\partial Y_{1}}{\partial X_{2}}\left(\frac{\partial X_{2}}{\partial t_{2}}+\frac{\partial X_{2}}{\partial I_{2}} \frac{d S_{2}}{d t_{2}}\right)\right]+\frac{\partial U_{1}}{\partial \phi_{2}} \frac{\partial \phi_{2}}{\partial X_{2}}\left[\frac{\partial X_{2}}{\partial t_{2}}+\frac{\partial X_{2}}{\partial I_{2}} \frac{d S_{2}}{d t_{2}}\right]=0
\end{aligned}
$$

In order to derive country 1's optimal choice of $t_{2}$, we insert (7) and (8) aggregated over all households in country 1 and the derivative of the budget constraint for $t_{2}$, which is $\frac{\partial X_{1}}{\partial t_{2}}+\frac{\partial Y_{1}}{\partial t_{2}}=-\frac{\partial S_{2}}{\partial t_{2}}$ into (13). Then we obtain

$$
\left(t_{1} \frac{\partial X_{1}}{\partial X_{2}}+\frac{\frac{\partial U_{1}}{\partial \phi_{11} \partial \phi_{11}}+\frac{\partial U_{1} \partial \phi_{2}}{\partial \phi_{2} \partial X_{1}}}{\lambda} \frac{\partial X_{1}}{\partial X_{2}}+\frac{\frac{\partial U_{1} \partial \phi_{2}}{\partial \phi_{2} \partial X_{2}}}{\lambda}\right)\left(\frac{d X_{2}}{d t_{2}}+\frac{\partial X_{2}}{\partial I_{2}} \frac{d S_{2}}{d t_{2}}\right)=\frac{\partial S_{2}}{\partial t_{2}}
$$

In the simultaneous move game country 2 in turn counterbids a contract to country 1 so that we can write the following system of equations:

$$
\begin{aligned}
& \frac{\partial S_{2}}{\partial t_{2}}\left[1-\left(t_{1} \frac{\partial X_{1}}{\partial X_{2}}+\frac{\frac{\partial U_{1}}{\partial \phi_{11}} \frac{\partial \phi_{11}}{\partial X_{1}}+\frac{\partial U_{1}}{\partial \phi_{2}} \frac{\partial \phi_{2}}{\partial X_{1}}}{\lambda} \frac{\partial X_{1}}{\partial X_{2}}+\frac{\frac{\partial U_{1}}{\partial \phi_{2}} \frac{\partial \phi_{2}}{\partial X_{2}}}{\lambda}\right) \frac{\partial X_{2}}{\partial I_{2}}\right] \\
& =\left(t_{1} \frac{\partial X_{1}}{\partial X_{2}}+\frac{\frac{\partial U_{1} \partial \phi_{11}}{\partial \phi_{11} \partial X_{1}}+\frac{\partial U_{1} \partial \phi_{2}}{\partial \phi_{2} \partial X_{1}}}{\lambda} \frac{\partial X_{1}}{\partial X_{2}}+\frac{\frac{\partial U_{1} \partial \phi_{2}}{\partial \phi_{2} \partial X_{2}}}{\lambda}\right) \frac{d X_{2}}{d t_{2}} \\
& \frac{\partial \mathrm{S}_{1}}{\partial \mathrm{t}_{1}}\left[1-\left(\mathrm{t}_{2} \frac{\partial \mathrm{X}_{2}}{\partial \mathrm{X}_{1}}+\frac{\frac{\partial \mathrm{U}_{2}}{\partial \phi_{12}} \frac{\partial \phi_{12}}{\partial \mathrm{X}_{2}}+\frac{\partial \mathrm{U}_{2}}{\partial \phi_{2}} \frac{\partial \phi_{2}}{\partial \mathrm{X}_{2}}}{\lambda} \frac{\partial \mathrm{X}_{2}}{\partial \mathrm{X}_{1}}+\frac{\frac{\partial \mathrm{U}_{2}}{\partial \phi_{2}} \frac{\partial \phi_{2}}{\partial \mathrm{X}_{1}}}{\lambda}\right) \frac{\partial \mathrm{X}_{1}}{\partial \mathrm{I}_{1}}\right]= \\
& \left(t_{2} \frac{\partial X_{2}}{\partial X_{1}}+\frac{\frac{\partial U_{2}}{\partial \phi_{12}} \frac{\partial \phi_{12}}{\partial X_{2}}+\frac{\partial U_{2}}{\partial \phi_{2}} \frac{\partial \phi_{2}}{\partial X_{2}}}{\lambda} \frac{\partial X_{2}}{\partial X_{1}}+\frac{\frac{\partial U_{2}}{\partial \phi_{2}} \frac{\partial \phi_{2}}{\partial X_{1}}}{\lambda}\right) \frac{d X_{1}}{d t_{1}}
\end{aligned}
$$


Inserting equation (11) the equivalent marginal effect for country 1 into the system of equations (15) shows that the two countries with reciprocal spillovereffects can coordinate to play a first-best optimal eco-tax policy by a system of take-it-or-leave-it offers:

$$
\begin{aligned}
& t_{1}^{*}=\frac{\frac{\partial U_{1}}{\partial \phi_{11}} \partial \phi_{11}+\frac{\partial U_{1} \partial \phi_{2}}{\partial \phi_{2} \partial X_{1}}+\frac{\partial U_{2} \partial \phi_{2}}{\partial \phi_{2} \partial X_{1}}}{\lambda} \\
& t_{2}^{*}=\frac{\frac{\partial U_{2}}{\partial \phi_{12}} \partial \phi_{12} \partial X_{2}+\frac{\partial U_{2} \partial \phi_{2}}{\partial \phi_{2} \partial X_{2}}+\frac{\partial U_{1} \partial \phi_{2}}{\partial \phi_{2} \partial X_{2}}}{\lambda}
\end{aligned}
$$

In the proposed efficiency-generating scheme, transfers are financed by revenues raised from Pigouvian taxes, which are imposed within each country. Any excess tax revenue can be redistributed to households using lump-sum transfers. However, not necessarily the revenues cover the required funds required for the transfers. In such a case the mechanism may not lead to a full internalization of the spillovers.

\section{Numerical Simulations for the Proposed Scheme}

\subsection{Setting up the Problem}

The inclusion of ancillary benefits, which are private to a region or country, will raise the tax-income and therefore the funds available for transfers as long as the price elasticity of demand for consuming the polluting good is not very high. In order to analyse whether the proposed international negotiation scheme is viable, we employ a simulation model. In doing this we especially consider the influence which ancillary benefits have on the functionality of the scheme (see the Appendix for a survey on all relevant variables of the model).

In line with the model of the previous section we consider a setting with two countries, producing two goods (X and $\mathrm{Y}$ ), a clean good that generates no emissions and a dirty good that generates emissions. Abatement of GHG emissions contributes to the global public good $Q_{2}$, i.e. climate stabilization. 
Moreover, the abatement of sedentary emissions like noise and air pollution is a local public good due to its limited geographical sphere of influence. Hence, for notational simplicity without loss of generality we maytake into account a modified welfare function depending on the provision of local as well as global public goods (respectively $\mathrm{Q}_{1}$ and $\mathrm{Q}_{2}$ ). Further we assume that there is a fixed amount of an input ( $\mathrm{L}$ ) that is allocated to the production of the two goods. The aim is to achieve an optimal level of provision of both $\mathrm{X}$ and $\mathrm{Y}$ and of the local public good $\mathrm{Q}_{1}$ in each country, as well as the optimal provision of the global public good $\mathrm{Q}_{2}$.

\subsubsection{Link between the local public good $Q_{1 i}$ and emissions $\phi_{1 i}$}

First we consider the links between the public and private goods. The dirty private good $X_{i}$ generates emissions $\phi_{1 i}$ and $\phi_{2 i}$, while the clean private good $Y_{i}$ generates no emissions. The higher the emissions $\phi_{1 i}$, the lower will be the amount of the local public good. We use the following specific form:

$$
Q_{1 i}=\overline{Q_{1 l}} \cdot e^{-k_{1} \phi_{1 i}}: i=1 \text { or } 2 . X_{1 i} \geq 0, k_{1} \geq 0
$$

with increasing emissions $\phi_{1 i}$ the local public good supply declines at a decreasing rate, in line with empirical observations. The relationship between $Q_{1 i}$ and $\phi_{1 i}$ is shown in Figure 2 .

\subsubsection{Link between local emissions $\phi_{1 i}$ and global emissions $\phi_{2 i}$}

For simplicity we assume that local and global emissions are produced in constant proportion to each other:

$$
\phi_{2 i}=\delta \cdot \phi_{1 i}, \quad \delta>0 .
$$

\subsubsection{Link between global emissions and the global public good $Q_{2}$}

The supply of the global public good declines if the total quantity of global emissions increases:

$$
Q_{2}=\overline{Q_{2}} e^{-k_{2}\left(\phi_{21}+\phi_{22}\right)}, \quad k_{2}>0 .
$$


In analogy to the treatment of local public goods we consider a relationship between $Q_{2}$ and $\phi_{2}=\phi_{21}+\phi_{22}$ with diminishing returns of abatement with the exception that the value of $Q_{2}$ depends on the sum of emissions in the two countries.

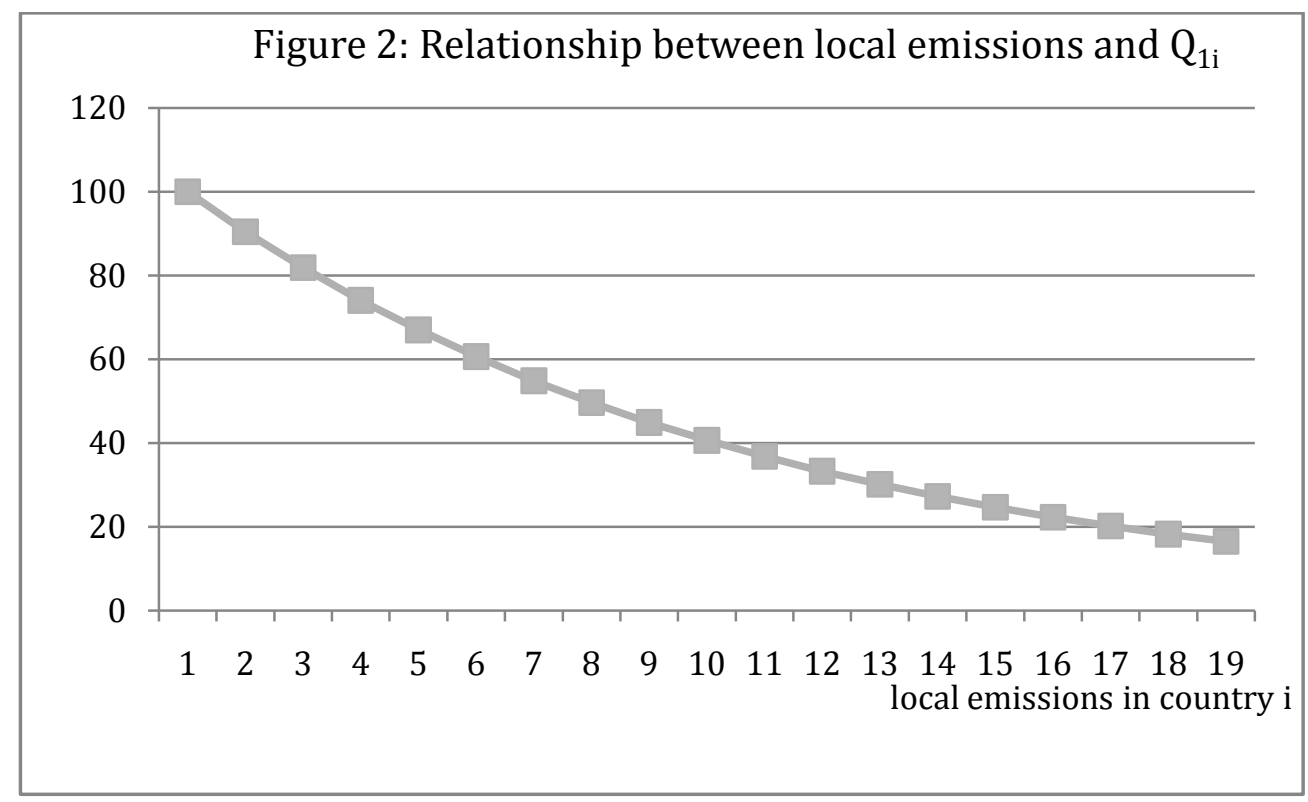

5.1.4 Links between $\phi_{1 i}$ and the dirty private good $X_{i}$

The trade-off between the level of the emissions $\phi_{1 i}$ and the amount of $X_{i}$ is depicted as follows:

$$
\begin{aligned}
& X_{i}=C \cdot\left(\omega_{i} L_{i}\right)^{\gamma} \cdot \phi_{1 i}^{v} \\
& 1 \geq v \geq 0 \\
& 1 \geq \gamma \geq 0 \\
& 1 \geq \omega_{i} \geq 0 \\
& C>0 \\
& \phi_{1 i} \leq \bar{X}_{l} \\
& i=1 \text { or } 2,
\end{aligned}
$$

where $\omega$ is the share of the fixed resource allocated to the dirty private good.

By equation (21) there are diminishing returns to $\phi_{1 i}$ in terms of producing $X_{i}$. In this framework we can interpret local emissions $\phi_{1 i}$ as an input to producing $X_{i}$, or in terms of the resources needed to reduce $\phi_{1 i}$ from its maximum value of 
$\bar{X}_{l}$. Further, there are also non-increasing returns to the use of production resources L.

The function takes the form shown in Figure 3.

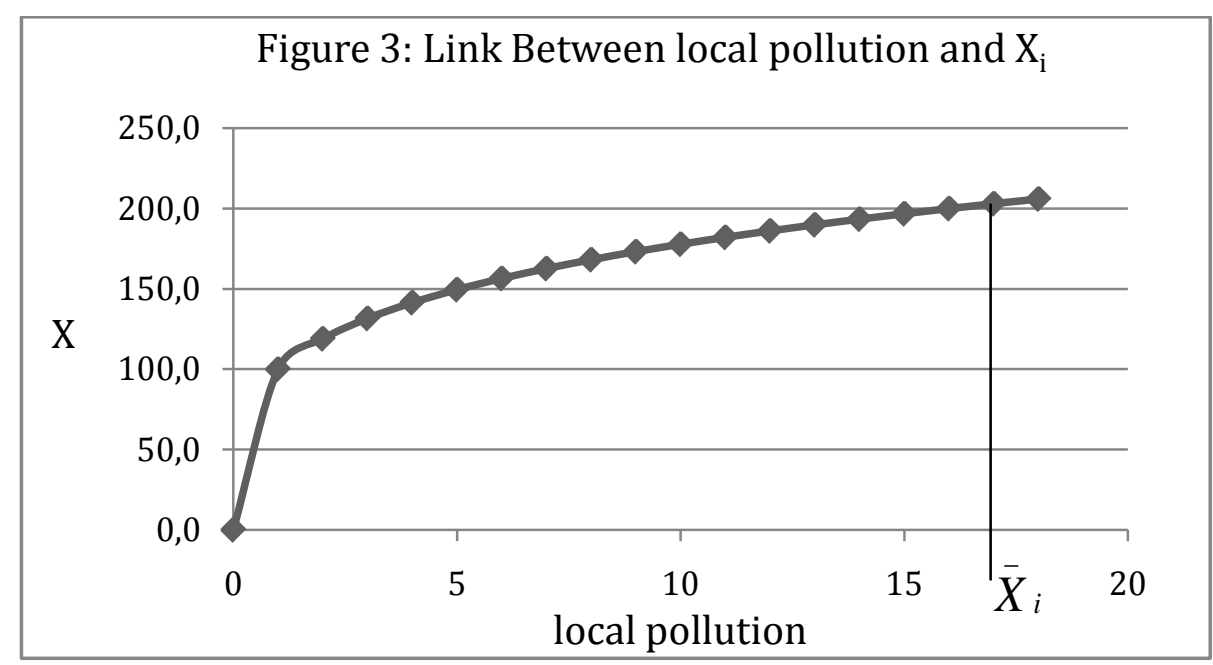

\subsubsection{Determinants of $Y_{i}$}

We assume that the supply of the clean private good $Y_{i}$ depends on the share of production resources which are used for its production.

$$
\begin{aligned}
& Y_{i}=D \cdot\left(\left(1-\omega_{i}\right) L_{i}\right)^{\varepsilon} \\
& 1 \geq \varepsilon \geq 0 \\
& 1 \geq \omega_{i} \geq 0 \\
& D>0 \\
& i=1 \text { or } 2 .
\end{aligned}
$$

By equation (22) the underlying production function exhibits non-increasing returns to scale.

\subsubsection{The national welfare function}

We define the welfare function for each country as a linear-homogenous utility function given by:

$$
U_{i}=Q_{1 i}^{\alpha} Q_{2}^{\beta} X_{i}^{\mu} Y_{i}^{(1-\alpha-\beta-\mu)}, \quad i=1 \text { or } 2 .
$$


The parameters $\alpha$ and $\beta$ reflect the strength of preferences for the local and global public good in the country. For simplicity we assume that these preferences are the same for both countries.

\subsection{Determining Outputs: The Cournot-Nash (CN) Solution}

Basically, the CN solution is based on the assumption that each country is maximising its utility for a given strategy of the opponent player. In this respect the welfare of each country is affected by the GHG-emissions $\phi_{2}$ produced in the other country. Each country's decision can be reduced to choosing $\phi_{1}$. The firstorder conditions for the maximum are:

$$
\begin{aligned}
& \frac{\partial U_{i}}{\partial \phi_{1 i}}=\frac{\alpha U_{i}}{Q_{1 i}} \frac{\partial Q_{1 i}}{\partial \phi_{1 i}}-\frac{\beta U_{i}}{Q_{2}} \frac{\partial Q_{2}}{\partial \phi_{1 i}}+\frac{\mu U_{i}}{X_{i}} \frac{\partial X_{i}}{\partial \phi_{1 i}}=0 \\
& \frac{\partial U_{i}}{\partial \omega_{i}}=\frac{\mu U_{i}}{X_{i}} \frac{\partial X_{i}}{\partial \omega_{i}}+\frac{(1-\alpha-\beta-\mu) U_{i}}{Y_{i}} \frac{\partial Y_{i}}{\partial \omega_{i}}=0 .
\end{aligned}
$$

From (18) we can derive:

$$
\frac{\partial Q_{1 i}}{\partial \phi_{1 i}} \frac{1}{Q_{1 i}}=-k_{1}
$$

and from (19) and (20)

$$
\frac{\partial Q_{2}}{\partial \phi_{1 i}} \frac{1}{Q_{2}}=-\delta k_{2}
$$

and from (21) we obtain

$$
\frac{\partial X_{i}}{\partial \phi_{1 i}} \frac{1}{X_{i}}=\frac{v}{\phi_{1 i}} .
$$

By substituting (26) - (28) into (24) and dividing by $U_{i}>0$ we get: 


$$
-\alpha k_{1}-\beta \delta k_{2}+\mu \frac{v}{\phi_{1 i}}=0
$$

From (21) we have

$$
\frac{\partial X_{i}}{\partial \omega_{i}}=\frac{\gamma X_{i}}{\omega_{i}}
$$

and from (22) we obtain:

$$
\frac{\partial Y_{i}}{\partial \omega_{i}}=\frac{-\varepsilon Y_{i}}{\left(1-\omega_{i}\right)}
$$

Rearranging terms we can express the emission level in the Cournot-Nash game explicitly in closed form as:

$$
\phi_{1 i}^{C N}=\frac{(\mu) v}{\alpha k_{1}+\beta \delta k_{2}}
$$

And similarly we can express the share of productive resources to $X$ as

$$
\omega_{i}^{C N}=\frac{\mu \gamma}{(\mu \gamma+((1-\alpha-\beta-\mu)) \varepsilon)^{\prime}}
$$

where the superscripts $C N$ indicates that that is the Cournot-Nash solution. Note that the first order conditions may not give the maximum and we have possible non-concavities. Hence, we also need to consider the corner solution with no reductions in $\phi_{1 i}: 6$

$$
\phi_{1 i}^{C N}=\bar{X}_{l}
$$

\footnotetext{
${ }^{6}$ We can exclude the case of $\phi_{1 i}=0$ as a possible solution as that would imply $X_{i}=0$, which would require no consumption of the dirty private good. With a Cobb-Douglas utility function that is not possible.
} 


\subsection{Observations on the CN Solution}

a) The greater is the cost of abatement of both the local and global public goods, in terms of the size of $v$, the higher will be the level of local emissions $\phi_{1 i}$ and GHG emissions $\phi_{2 i}$. This follows straightforwardly from equation (32).

b) By setting $\alpha$ equal to zero we may represent the scenario where the provision of local public goods is not an issue. In that case the level of $\phi_{1 i}$ will be higher than if $\alpha$ is positive. In other words, the greater the importance that the local public good has in terms of preferences, the lower will be the selected level of local emissions, and since local and global emissions are linked, the lower will be the selected level of global emissions. This can be derived from equation (32).

c) The allocation of productive resources to the polluting private good will be higher the greater is the preference for that good (the preferences for the polluting private good are measured by the parameter $\mu$ ). This follows after some manipulation from equation (33). Likewise, the higher are the preferences for local and global public goods, the less will be allocated to the polluting private good. Finally the greater is the value of $\varepsilon$, the less we have diminishing returns in the production of the clean good and the more will be allocated to the production of that good.

d) The $C N$ solution will not emerge from a market equilibrium because private producers will not take account of the production of emissions that reduce the amounts of the local and global public good. It is easy to show that the level of $\phi_{1 i}$ and $\phi_{2 i}$ will be given by: ${ }^{7}$

$$
\begin{aligned}
\phi_{1 i} & =\bar{X}_{\imath} \\
\phi_{2 i} & =\delta \bar{X}_{\imath}
\end{aligned}
$$

under the $C N$ solution.

However in the $\mathrm{CN}$ game countries can attain the $\mathrm{CN}$ solution if they levy a $\operatorname{tax} t^{C N}$ on $\phi_{1 i}$ as given by the expression below: 


$$
t^{C N}=C\left(\omega_{i}^{C N} L\right)^{\gamma}\left[\frac{(1-\alpha-\beta) v}{\alpha k_{1}+\beta \delta k_{2}}\right]^{(v-1)}
$$

where $\omega_{i}^{C N}$ is given by (33). ${ }^{8}$

\subsection{Optimal Choices: The Global Solution}

For the global solution we seek to optimise $W$, where:

$$
W=U_{1}+U_{2}
$$

We now take account of the impact of $\phi_{2 i}$ on the utility of country 2 and vice versa. If both countries are identical the optimal interior solution can now be shown to be:

$$
\phi_{1 i}^{0}=\frac{\mu v}{\alpha k_{1}+2 \beta \delta k_{2}} .
$$

The superscript $O$ stands for the optimal solution. A corner solution can again not be ruled out, so we must allow for the possibility that:

$$
\phi_{1 i}^{0}=\bar{X}_{\iota}, \quad i=1 \text { or } 2 \text {. }
$$

Comparing (38) and (39) against (32) and (33) we can state that:

$$
\phi_{1 i}^{0} \leq \phi_{1 i}^{C N}
$$

It can also be confirmed that the optimal value of $\mathrm{s}$ is the same as in the $C N$ solution, i.e. it is given by (33).

\subsection{Some Numerical Results for Two Identical Countries}

Table 1 shows the results for plausible values of the parameters for two identical countries. The main points to note are the following:

${ }^{8}$ In this case the price of $\mathrm{X}$ is taken as the numéraire and set at one. 
(i) Corner solutions (when the reductions in $\phi_{1 i}$ and $\phi_{2 i}$ are zero) do not arise in the Cournot Case. For the parameters investigated this is never the case.

(ii) Increases in the value of $\alpha$ (the preference for the impure public good) increase the $C N$ as well as the optimal level of reduction, as do increases in the value of $\beta$ (the preference for the pure global public good).

(iii) Reductions in output relative to the maximum possible output are of the order of $30 \%$ in the $C N$ case and of the order of one percent more in the optimal case.

(iv) Increases in $k_{1}$ (the rate at which the quality of the local environment declines with increases in local emissions) and $k_{2}$ (the rate at which the quality of the global environment declines with increases in global emissions) result in an increase in the reduction in the both local and global emissions. The results are quite sensitive to these parameters.

Table 1: $\quad$ Numerical Values for the Two-Country Impure Public Good Model

\begin{tabular}{|c|c|c|c|c|c|c|c|c|c|c|}
\hline \multirow[b]{2}{*}{$\alpha$} & \multicolumn{4}{|c|}{ Variation in $\alpha$ and $\beta$} & \multicolumn{2}{|c|}{ Variation in $\mathrm{v}$} & \multicolumn{4}{|c|}{ Variation in $k_{1}$ and $k_{2}$} \\
\hline & 0 & 0.025 & 0.05 & 0.025 & 0.025 & 0.025 & 0.025 & 0.025 & 0.025 & 0.025 \\
\hline$\beta$ & $\begin{array}{r}0.02 \\
5\end{array}$ & 0.025 & 0.025 & 0.05 & 0.025 & 0.025 & 0.025 & 0.025 & 0.025 & 0.025 \\
\hline$\mu$ & 0.4 & 0.4 & 0.4 & 0.4 & 0.4 & 0.4 & 0.4 & 0.4 & 0.4 & 0.4 \\
\hline$\varepsilon$ & 0.8 & 0.8 & 0.8 & 0.8 & 0.8 & 0.8 & 0.8 & 0.8 & 0.8 & 0.8 \\
\hline$\gamma$ & 0.8 & 0.8 & 0.8 & 0.8 & 0.8 & 0.8 & 0.8 & 0.8 & 0.8 & 0.8 \\
\hline$k_{1}$ & 1 & 1 & 1 & 1 & 1 & 1 & 2 & 0.5 & 1 & 1 \\
\hline$k_{2}$ & 0.75 & 0.75 & 0.75 & 0.75 & 0.75 & 0.75 & 0.75 & 0.75 & 2 & 0.25 \\
\hline$v$ & $\begin{array}{r}0.02 \\
5 \\
\end{array}$ & 0.025 & 0.025 & 0.025 & 0.04 & 0.05 & 0.025 & 0.025 & 0.025 & 0.025 \\
\hline \multicolumn{11}{|l|}{$C N$ Solution } \\
\hline$\%$ Red. $\operatorname{In} \phi_{1 i}$ & $-47 \%$ & $-77 \%$ & $-85 \%$ & $-84 \%$ & $-63 \%$ & $-54 \%$ & $-85 \%$ & $-68 \%$ & $-87 \%$ & $-68 \%$ \\
\hline$\%$ Red. in $\phi_{2 i}$ & $-47 \%$ & $-77 \%$ & $-85 \%$ & $-84 \%$ & $-63 \%$ & $-54 \%$ & $-65 \%$ & $-24 \%$ & $-68 \%$ & $-24 \%$ \\
\hline$\%$ Red. in $X_{i}$ & $-31 \%$ & $-32 \%$ & $-32 \%$ & $-32 \%$ & $-32 \%$ & $-32 \%$ & $-33 \%$ & $-31 \%$ & $-33 \%$ & $-31 \%$ \\
\hline \multicolumn{11}{|l|}{$\begin{array}{l}\text { Optimal } \\
\text { Solution } \\
\end{array}$} \\
\hline$\%$ Red. in $\phi_{1 i}$ & $-73 \%$ & $-84 \%$ & $-89 \%$ & $-90 \%$ & $-74 \%$ & $-68 \%$ & $-89 \%$ & $-80 \%$ & $-92 \%$ & $-73 \%$ \\
\hline$\%$ Red. in $\phi_{2 i}$ & $-73 \%$ & $-84 \%$ & $-89 \%$ & $-90 \%$ & $-74 \%$ & $-68 \%$ & $-89 \%$ & $-80 \%$ & $-92 \%$ & $-73 \%$ \\
\hline \% Red. in $X_{i}$ & $-32 \%$ & $-32 \%$ & $-32 \%$ & $-32 \%$ & $-33 \%$ & $-33 \%$ & $-33 \%$ & $-32 \%$ & $-34 \%$ & $-32 \%$ \\
\hline
\end{tabular}




\subsection{Introducing a Tax to Emulate the Optimal Solution When Behaviour is Cournot Nash}

In this section we consider the introduction of a tax on $\phi_{2}$ (alternatively, a tax on $\phi_{1}$ may be raised which would have the same impact since the two pollutants are in fixed proportions). The tax is paid to the other country or to an international body. In return the first country receives a payment from the taxes collected in the second country or collected internationally.

The first thing to note is that an ad valorem tax on output will not have an impact on the $C N$ solution. The first order conditions do not change if the country maximises utility with net income defined as:

$$
\widehat{X}_{l}=(1-\lambda) X_{i},
$$

where $\widehat{X}_{l}$ is the net income and $\lambda$ is the tax rate. The tax that will modify behaviour is on emissions so that net income in units of $X$ is defined as:

$$
\widehat{X}_{l}=X_{i}-t_{i} \phi_{2 i},
$$

where $t_{i}$ is the unit tax on emissions $\phi_{2 i}$. For such a tax the first-order conditions for an interior solution are given by

$$
(\mu)\left[\frac{\left(v\left(\omega_{i} L\right)^{\gamma} \phi_{1 i}^{v-1}-\delta t_{i}\right)}{\left(\left(\omega_{i} L\right)^{\gamma} \phi_{1 i}^{v}-\delta t_{i}\right)}\right]=\alpha k_{1}+\beta \delta k_{2} \text {. }
$$

When $t_{i}$ is zero this collapses to (29), giving the solution as expressed in (32). Equation (43) is shown graphically in Figure 4. The LHS declines with $\phi_{1 i}$ and with $t_{1}$, so the higher the tax, the lower are the chosen level of $\phi_{1 i}$. 
Figure 4: A tax on the polluting private good

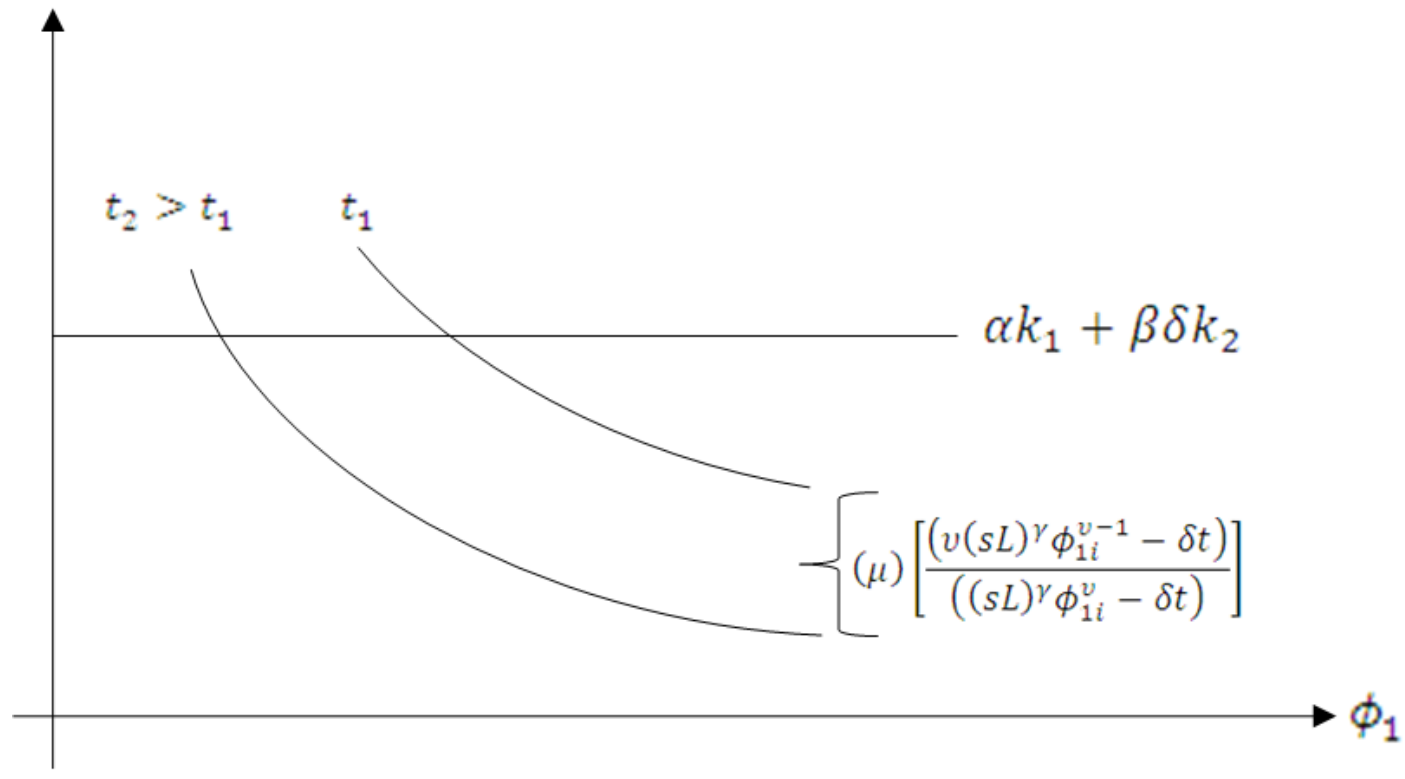

The level of $t$ cannot be determined in closed form. Any country will only accept the proposed tax policy if it goes along with a higher level of welfare than the one in the $\mathrm{CN}$ solution. We can confirm that if the countries are identical and if the tax is fully recycled, so that lump sum receipts are equal to payments made, then the welfare with the tax will indeed be equal to that at the global optimum and that is higher than welfare at the $C N$ solution.

Simulations results are given in Table 2 for the tax rates that bring the $C N$ solution to the optimal one. The tax rate is expressed in terms of the price of output being one. Hence it can be stated as a percentage rate on the output of $X_{i}$.

Table 2: Tax Rates on Global Pollutant That Take CN Solution to the Optimal One

\begin{tabular}{|c|r|r|r|r|r|r|r|r|r|r|}
\hline & \multicolumn{4}{|c|}{ Variation in $\alpha$ and $\beta$} & \multicolumn{3}{|c|}{ Variation in $v$} & \multicolumn{3}{|c|}{ Variation in $k_{1}$ and $k_{2}$} \\
\hline$\alpha$ & 0 & 0.025 & 0.05 & 0.025 & 0.025 & 0.025 & 0.025 & 0.025 & 0.025 & 0.025 \\
\hline$\beta$ & 0.025 & 0.025 & 0.025 & 0.05 & 0.025 & 0.025 & 0.025 & 0.025 & 0.025 & 0.025 \\
\hline $\mathrm{k}_{1}$ & 1 & 1 & 1 & 1 & 1 & 1 & 2 & 0.5 & 1 & 1 \\
\hline $\mathrm{k}_{2}$ & 0.75 & 0.75 & 0.75 & 0.75 & 0.75 & 0.75 & 0.75 & 0.75 & 2 & 0.25 \\
\hline$v$ & 0.025 & 0.025 & 0.025 & 0.025 & 0.04 & 0.05 & 0.025 & 0.025 & 0.025 & 0.025 \\
\hline Tax Rate & $2.25 \%$ & $2.28 \%$ & $2.32 \%$ & $4.60 \%$ & $2.28 \%$ & $2.30 \%$ & $2.27 \%$ & $2.29 \%$ & $5.96 \%$ & $0.77 \%$ \\
\hline
\end{tabular}


We may derive the following statements form the solutions of Table 2:

a) The tax rates on the local pollutant are in the range of one to five percent of the output of the dirty good.

b) In the case of no impure public good problem $(\alpha=0)$, the tax rate is lower than when there is a public good problem (all else being equal). But the additional impact is not large and increases in $\alpha$ from 0.025 to 0.05 do not generate any appreciable increase in the tax rate.

c) Taxes rates do go up sharply when $\beta$ increases: from 0.025 to 0.05 increases the rate from $2 \%$ to $4 \%$. Recall that $\beta$ is a measure of the preference for the global public good.

d) Variations in $\mathrm{v}$, the marginal cost of abatement of the local public good, do not appear to change this tax rate appreciably.

e) Variations in $\mathrm{k}_{2}$ (the rate at which increases in emissions reduce the global public good) have a major impact on the tax rate. Reducing the value of $\mathrm{k}_{2}$ from 0.75 to 0.25 reduces the tax rate from $2.3 \%$ to $0.7 \%$ and rising the value to 2.0 increases the tax rate from $2 \%$ to $6 \%$.

Recapitulating, the analysis has shown that the presence of both local and global public goods yields a Cournot-Nash solution as well as a global solution in which the presence of the local public good does have an impact. If we want to go from the $\mathrm{CN}$ to global optima, a tax on the global pollutant is one way of getting there. The lump-sum repayment outweighs this tax burden and as long as countries are identical we can show that the tax revenue is sufficient to guarantee that the welfare level with the tax and repayment is equal to that of the global optimum (and higher than that of the $\mathrm{CN}$ solution).

\section{Concluding Remarks}

Ancillary benefits are an important benefit category associated with climate policy (Pearce 2000). Therefore, their influence on current international efforts should be carefully assessed. In a scheme combining Pigouvian taxes and sidepayments, we investigate how ancillary benefits might influence the outcome of negotiations. 
Ancillary benefits imply a higher attractiveness of climate policy, generating higher demands for such policies and consequently justifying higher environmental tax rates in the considered tax-transfer scheme. Since the international side-payments are financed via the environmental taxation, more financial scope for transfers and room for manoeuvre are present. Yet, as the numerical simulation results for identical agents demonstrated, the international tax-transfer system to attain an efficient climate stabilisation level will even largely work in a proper way when ancillary effects are disregarded. The change from the Nash equilibrium to a Pareto-optimal outcome raises global welfare and hence there are surpluses, which suffice to attain an outcome where no country suffers from the scheme. In order to reach this outcome, the surpluses, however, have to be redistributed via the transfers-scheme.

As we found in our simulation model, ancillary effects tend to justify only moderately higher tax rates and therefore the additional tax income available for international transfers does not increase significantly. However, if we take into account not only environmental co-benefits like improved air-pollution and lower noise levels, but also, e.g., a rise in energy security due to a higher supply of domestic renewable energy use, the ancillary benefits might gain further weight. As Gupta (2010: 645) points out considering past international climate policy, energy security is even a more dominant issue than climate change.

Yet, if we take into account that the primary benefits are uncertain and are largely not enjoyed by current generations, there is some political reluctance to invest in climate policy. The difficulty for decision-makers to justify investments in climate protection projects bringing about uncertain future benefits is a challenging task by itself, but the high public debt levels faced in many countries exacerbate it. In contrast to primary benefits, ancillary benefits constitute an immediate payback of investments, so that long-term periods for amortization of debts are prevented. Investment benefits materialize immediately, since cost, e.g. from noise and local air pollution, for the climate protecting country are prevented in the present.

Whether the use of discount factors is an appropriate way to reflect the high relevance of ancillary benefits for policy making is hard to say and there is much dispute about this (see, e.g. Schelling 1995). Furthermore, some of those 
countries facing serious financial trouble recently even had problems in receiving sufficient loans at all. For such countries a long-term period for the amortization of investments in climate policy will probably be unacceptable.

Therefore, although ancillary benefits might be moderate compared to primary benefits, they may have an important impact on governments' readiness to invest in climate policy. Overall benefits from such investments start flow immediately due to the occurrence of ancillary effects. 


\section{References}

Altemeyer-Bartscher, M.; Rübbelke, D.T.G. and Sheshinski, E. (2010): Environmental Protection and the Private Provision of International Public Goods. Economica, Vol. 77, 775-784.

Andreoni, J . and Bergstrom, T. C. (1996): Do Government Subsidies Increase the Private Supply of Public Goods?. Public Choice, Vol. 88, 295-308.

Barrett, S. (1990): The Problem of Global Environmental Protection. Oxford Review of Economic Policy, Vol. 6, 68-79.

Boadway, R.; Song, Z. and Tremblay, J .-F. (2007): Commitment and Matching Contributions to Public Goods. J ournal of Public Economics, Vol. 91, 16641683.

Boadway, R.; Song, Z. and Tremblay, J.-F. (2011): The Efficiency of Voluntary Pollution Abatement when Countries Can Commit. European Journal of Political Economy, 27, 352-368.

Brons, M., Nijkamp, P., Pels, E. and Rietveld, P. (2008): A Meta-analysis of the Price Elasticity of Gasoline Demand. A SUR Approach. Energy Economics, Vol. 30, 2105- 2122.

Buchholz, W.; Cornes, R. C. and Rübbelke, D. (2011): Interior Matching Equilibria in a Public Good Economy: An Aggregative Game Approach. J ournal of Public Economics, Vol. 95, 639-645.

Cornes, R.C. and Sandler, T. (1994): The Comparative Static Properties of the Impure Public Good Model. J ournal of Public Economics, Vol. 54, 403-421.

Cornes, R. C. and Sandler, T. (1996), The Theory of Externalities, Public Goods and Club Goods, Cambridge University Press (Cambridge).

IPCC (2001): Climate Change 2001 - Mitigation. Cambridge University Press, Cambridge.

Ekins P. (1996): The Secondary Benefits of $\mathrm{CO}_{2}$ Abatement: Hiw Much Emission Reduction Do They J ustify?. Ecological Economics, Vol. 16, 13-24.

Falkinger, J . (1996): Efficient Private Provision of Public Goods by Rewarding Deviations from Average. J ournal of Public Economics, Vol. 62, 413-422.

Falkinger, J.; Hackl, F. and Pruckner, G.J. (1996): A Fair Mechanism for Efficient Reduction of Global $\mathrm{CO}_{2}$-Emissions. FinanzArchiv/Public Finance Analysis, Vol. 53, 308-331.

Finus, M. and Tjøtta, S. (2003): The Oslo Protocol on Sulfur Reduction: the Great Leap Forward?. J ournal of Public Economics, Vol. 87, 2031-2048.

Fujita, T. (2011): Realization of a Self-enforcing International Environmental Agreement by Matching Schemes, Discussion Paper 2011-02, Faculty of Economics, Kyushu University.

Gupta, J. (2010): A History of International Climate Change Policy. WIREs Climate Change, Vol. 1, 636-653.

Guttman, J.M. (1978): Understanding Collective Action: Matching Behavior. American Economic Review, Vol. 68, 251-255.

Guttman, J.M. (1987): A Non-Cournot Model of Voluntary Collective Action. Economica, Vol. 54, 1-19. 
Kotchen, M.J . (2005): Impure Public Goods and the Comparative Statics of Environmentally Friendly Consumption. Journal of Environmental Economics and Management, Vol. 49, 281-300.

Kotchen, M.J . (2006): Green Markets and Private Provision of Public Goods. J ournal of Political Economy, Vol. 114, 816-834.

Longo, A.; Hoyos, D. and Markandya, A. (2011): Willingness to Pay for Ancillary Benefits of Climate Change Mitigation. Environmental and Resource Economics, Online First.

Markandya, A. and Rübbelke, D.T.G. (2004): Ancillary Benefits of Climate Policy. J ahrbücher für Nationalökonomie und Statistik, Vol. 224, 488-503.

Nordhaus, W.D. (2006): After Kyoto: Alternative Mechanisms to Control Global Warming. American Economic Review, Vol. 96, 31-34.

OECD (2000): Ancillary Benefits and Costs of Greenhouse Gas Mitigation, Paris.

Pearce, D. (2000): Policy Framework for the Ancillary Benefits of Climate Change Policies, in: Ancillary Benefits and Costs of Greenhouse Gas Mitigation, OECD, Paris, 517-560.

Rübbelke, D.T.G. (2003): An Analysis of Differing Abatement Incentives. Resource and Energy Economics, Vol. 25, 269-295.

Rübbelke, D.T.G. (2006): An Analysis of an International Environmental Matching Agreement. Environmental Economics and Policy Studies, Vol. 8, 1-31.

Rübbelke, D.T.G. and Sheshinski, E. (2005): Transfers as a Means to Combat European Spillovers. Jahrbücher für Nationalökonomie und Statistik, Vol. 225, 699-710.

Schelling, T.C. (1995): Intergenerational Discounting. Energy Policy, Vol. 23, 395-401. 


\section{Appendix:}

Table 3:

\begin{tabular}{|l|l|}
\hline Variable & Definition \\
\hline$\phi_{11}=\phi_{11}\left(X_{1}\right)$ & Quantity of emissions produced by country 1 which only affect country 1 \\
\hline$\phi_{21}=\phi_{21}\left(X_{1}\right)$ & Quantity of the emissions produced by country 1, which have a global effect. \\
\hline$X_{1}$ & Output of the 'dirty' private good produced by country 1 \\
\hline$Y_{1}$ & Output of the 'clean' private good produced by country 1 \\
\hline$\omega_{1}$ & $\begin{array}{l}\text { Share of production resources allocated to production of the 'dirty' good } \mathrm{X}_{1} \text { in } \\
\text { country 1 }\end{array}$ \\
\hline $1-\omega_{1}$ & $\begin{array}{l}\text { Share of production resources allocated to production of the 'clean' good } \mathrm{Y}_{1} \text { in } \\
\text { country 1 }\end{array}$ \\
\hline$\omega_{2}$ & $\begin{array}{l}\text { Share of production resources allocated to production of the 'dirty' good } \mathrm{X}_{2} \text { in } \\
\text { country 2 }\end{array}$ \\
\hline $1-\omega_{2}$ & $\begin{array}{l}\text { Share of production resources allocated to production of the 'clean' good } \mathrm{Y}_{2} \text { in } \\
\text { country 2 }\end{array}$ \\
\hline$\phi_{12}=\phi_{12}\left(X_{2}\right)$ & Quantity of emissions produced by country 2 which only affect country 2 \\
\hline$\phi_{21}=\phi_{21}\left(X_{2}\right)$ & Quantity of the emissions produced by country 2, which have a global effect \\
\hline$X_{2}$ & Output of the 'dirty' private good produced by country 2 \\
\hline$Y_{2}$ & Output of the 'clean' private good produced by country 2 \\
\hline$Q_{11}$ & Quantity of the local public good, available to country 1 \\
\hline$Q_{12}$ & Quantity of the local public good, available to country 2 \\
\hline$Q_{2}$ & Quantity of the global public good available to both countries 1 and 2 \\
\hline$L_{1}$ & Total quantity of productive resources available in country 1 \\
\hline$L_{2}$ & Total quantity of productive resources available in country 2 \\
\hline
\end{tabular}




\title{
BC3 WORKING PAPER SERIES
}

\author{
Basque Centre for Climate Change (BC3), Bilbao, Spain
}

The BC3 Working Paper Series is available on the internet at the following addresses:

http://www.bc3research.org/lits_publications.html

http://ideas.repec.org/s/bcc/wpaper.html

BC3 Working Papers available (see website for full list):

Elena Ojea, Julia Martin-Ortega and Aline Chiabai: Classifying Ecosystem Services for Economic Valuation: the Case of Forest Water Services

Aline Chiabai, Chiara Travisi, Anil Markandya, Helen Ding, and Paulo Nunes: Economic Assessment of Forest Ecosystem Services Losses: Cost of Policy Inaction

Kaysara Khatun: Competing Ecosystem services: an Assessment of Carbon and Timber in the Tropical Forests of Central America

Karen Pittel and Dirk Rübbelke: Local and Global Externalities, Environmental Policies and Growth

Margherita Grasso, Matteo Manera, Aline Chiabai, and Anil Markandya: The Health Effects of Climate Change: A Survey of Recent Quantitative Research

Luis Mari Abadie, Ramon Arigoni Ortiz and Ibon Galarraga: The Determinants of Energy Efficiency Investments in the U.S.

Aline Chiabai, Dirk Rübbelke and Lisa Maurer: ICT Application in the Research for Environmental Sustainability

Roger Fouquet: Long Run Dynamics of Energy-Related External Costs

Dirk Rübbelke: International Support of Climate Change Policies in Developing Countries: Strategic, Moral and Fairness Aspects

Melanie Heugues: Endogenous Timing in Pollution Control: Stackelberg versus Cournot-Nash Equilibria

Roger Fouquet and Peter J.G. Pearson: The Long Run Demand for Lighting: Elasticities and Rebound Effects in Different Phases of Economic Development

Ibon Galarraga, David Heres Del Valle and Mikel González-Eguino: Price Premium for High-Efficiency Refrigerators and Calculation of Price-Elasticities for Close-Substitutes: Combining Hedonic Pricing and Demand Systems

Anil Markandya, Mikel González-Eguino, Patrick Criqui, Silvana Mima (2011), Low Climate Stabilisation under Diverse Growth and Convergence Scenarios 